\section{Investigation on antioxidants, free radical scavenger and lipid peroxidation activities of whole grains finger millet (Eleusine coracana L.)}

\author{
Abiodun Akeem Ajiboye, \\ Oyinade Aderoju Dedeke, \\ Folasade Comfort Adeyemo \\ Department of Plant Science and \\ Biotechnology, Federal University, \\ Oye-Ekiti, Ekiti State, Nigeria
}

\begin{abstract}
This study evaluates the antioxidant potential and free radical scavenging ability of whole grain finger millet. The crude extracts were obtained by cold maceration using $80 \%$ ethanol and methanol. Concentrated extracts were subjected to radicals of 2,2'-diphenyl-1-picrylhydrazyl hydrate (DPPH), hydrogen peroxide, nitric oxide (NO) and malondialdehyde, while the antioxidant constituents evaluated includes total phenol and flavonoid. The results revealed that whole grain finger millet contained $14.65 \pm 0.41$ and $38.19 \pm 0.60 \mathrm{mg}$ QUE/g sample of flavoniods, $36.46 \pm 1.09$ and $67.10 \pm 1.17 \mathrm{mg} \mathrm{GAE} / \mathrm{g}$ sample of total phenolics and $17.61 \pm 0.70$ and $35.89 \pm 1.32$ $\mathrm{mg} \mathrm{AAE} / \mathrm{g}$ sample of total antioxidant capacity for methanol and ethanol respectively. Ethanolic extract of whole finger millet scavenged above $50 \%$ hyrogen peroxide, NO and DPPH radicals. Hence, it terminated up to $8.97-65.16 \%$ lipid peroxidation reaction chain that may result from auto-oxidation, photo-oxidation and any other oxidation stress that may occur in plant and animal tissues. Therefore, pharmocology attention has to be given to finger millet which showed an effective antioxdants and antiradical capacities. Also, cultivation of finger millet should be encouraged by farmers.
\end{abstract}

\section{Introduction}

Finger millet (Eleusine coracana L.) is an important cereal in Nigeria; it constitute as a principal staple food for the population in this country especially the northern part of Nigeria. The estimate of production output for millet in 2008 was 9 million metric tonnes in Nigeria. ${ }^{1}$ Nigeria was ranked second in global millet production with an average annual production of 4-9 million metric tons. ${ }^{1}$ It possessed brick redcoloured seed coat and is generally used in form of the whole meal for preparation of traditional foods, such as Coco, Kunu, Tuwo, Madidi, Burukutu, Hura especially in Northern part of Nigeria. Finger millets are usually prepared from the whole grains, the dietary fibre, minerals, phenolics and vitamins concentrated in the seed coat form the part of the food and offer their nutritional and health benefits. ${ }^{2}$ Finger millet contains about $5-8 \%$ protein, $1-2 \%$ ether extractives, $65-75 \%$ carbohydrates, $15-20 \%$ dietary fibre and $2.5-3.5 \%$ minerals. It has the highest calcium content among all cereals $(344 \mathrm{mg} / 100 \mathrm{~g}){ }^{3}$

Oxidative stress occurs in plant due to abiotic stress such as salinity, heat, cold, drought etc. and humans. Antioxidants are our first line of defence against free radical damages, and are critical for maintaining optimum health and wellbeing of plants and animals. ${ }^{4}$ Oxygen is a highly reactive atom that is capable of becoming part of potentially damaging molecules commonly called free radicals. Free radicals are capable of attacking the healthy cells of the body, causing them to lose their structures and functions. To protect the cells, organs and systems against reactive oxygen species, animals, humans and plants have to involve in a highly sophisticated and complex antioxidant protection system. ${ }^{4}$ Protection against all of these processes is dependent upon the adequacy of various antioxidant substances that are derived either directly or indirectly from the diet. Also, for plant to survive well in harsh environmental condition, it needs antioxidant protection system. An inadequate intake of antioxidant nutrients may compromise survival, thus compounding overall oxidative stress. Oxidative damage to DNA, proteins, lipids and other macromolecules has been implicated in the pathogenesis of a wide variety of diseases. ${ }^{5}$ Dietary antioxidants such as Vitamin C and E are capable of neutralizing reactive oxygen species (ROS) in the aqueous phase before lipid peroxidation is initiated. Vitamin E, a major lipid-soluble antioxidant, is the most effective chainbreaking antioxidant within the cell membrane where it protects membrane fatty acids from lipid peroxidation. ${ }^{6}$

\section{Materials and Methods}

\section{Plant extraction}

Ten grams ( $10 \mathrm{~g})$ of the whole grains of finger millet was grinded into powder form, and was extracted using $200 \mathrm{~mL}$ of $80 \%$
Correspondence: Abiodun Akeem Ajiboye, Department of Plant Science and Biotechnology, Federal University Oye-Ekiti, Ekiti State, Nigeria,

Tel.: +234.8033660373.

E-mail: abiodun.ajiboye@fuoye.edu.ng

Key words: antioxidant potential, free radical scavengers, lipid peroxidation, finger millet.

Contributions: AAA conceived the idea, designed, wrote the draft; OAD designed, analysed, interpreted the data and revised similarly; FCA designed the article.

Conflict of interest: the authors declare no potential conflict of interest.

Received for publication: 8 July 2016. Revision received: 23 August 2016.

Accepted for publication: 23 August 2016.

This work is licensed under a Creative Commons Attribution-NonCommercial 4.0 International License (CC BY-NC 4.0).

(C) Copyright A.A. Ajiboye et al., 2017 Licensee PAGEPress srl, Italy

International Journal of Plant Biology 2017; 8:6684 doi:10.4081/pb.2017.6684

ethanol and methanol. Magnetic stirrer was used to accelerate the extraction process. The stock solution was concentrated in rotary evaporator under reduce pressure.

\section{Determination of antioxidant activities}

\section{Total phenolics}

Plant extract of about $0.1 \mathrm{~mL}$ was added to $0.9 \mathrm{~mL}$ of water and $0.2 \mathrm{~mL}$ of folin-ciocalteu's phenol reagent. The resulting mixture was voltexed. After 5 min of standing, $1.0 \mathrm{~mL}$ of $7 \%(\mathrm{w} / \mathrm{w}) \mathrm{Na}_{2} \mathrm{CO}_{3}$ solution was further added and the solution was then distilled to $2.5 \mathrm{~mL}$ before incubated for $90 \mathrm{~min}$ at room temperature. The absorbance against a negative control containing $1 \mathrm{~mL}$ of water in place of the sample was taken at $750 \mathrm{~nm}$. The standard used was the Gallic acid at $0.1 \mathrm{mg} / \mathrm{mL}$ in order to determine Gallic acid Equivalent (GAE) of sample. ${ }^{7}$

\section{Total flavonoid contents}

To determine flavonoids content, 0.1 $\mathrm{mL}$ of extracts and standard were mixed with $0.4 \mathrm{~mL}$ of distilled water. This was followed by addition of $0.1 \mathrm{~mL}$ of $5 \%$ sodium nitrite. After 5 minutes, $0.1 \mathrm{~mL}$ of $10 \%$ Aluminum Chloride and $0.2 \mathrm{~mL}$ of sodium hydroxide were added and the volume was made up to $2.5 \mathrm{~mL}$ with distilled water. The absorbance at $510 \mathrm{~nm}$ was measured against 
the blank. The total flavonoid content of the plant extracts were expressed as $\mathrm{mg}$ quercetin equivalents per gram of the plant extract is calculated as:

$$
X=\mathrm{q} \times \mathrm{V} / \mathrm{w}
$$

where:

$\mathrm{X}=$ Total content of flavonoid compound in quercetin equivalent

$\mathrm{q}=$ concentration of quercetin established from the standard curve

$\mathrm{V}=$ volume of extract $(\mathrm{mL})$

$\mathrm{w}=$ weight of the crude methanolic extract obtained.

\section{Total antioxidant capacity}

To $0.1 \mathrm{~mL}$ of extracts and standard solutions of ascorbic acid (20, 40, 60, 80, 100 $\mu \mathrm{g} / \mathrm{mL}), 1 \mathrm{~mL}$ of the reagent solution which consist of $0.6 \mathrm{M}$ sulphuric acid, $28 \mathrm{mM}$ sodium phosphate and $4 \mathrm{mM}$ ammonium molybdate were added. Thereafter, the reacting mixture was incubated in a water bath at $95^{\circ} \mathrm{C}$ for 90 minutes. The mixture was then allowed to stand, cool to room temperature and the absorbance was measured at $695 \mathrm{~nm}$ against a blank which consisted of the reacting mixture containing distilled water in place of the extract. The antioxidant activities of the extracts were expressed as an ascorbic acid equivalent (mg AAE/g of sample). This method was based on the reduction of Molybdenum (VI) to Molybdenum (V) by the extract and the subsequent formation of a green phosphate/Molybdenum (V) complex at an acidic $\mathrm{pH}^{8}$

\section{Determination of free radical scav- enging activities}

\section{2,2'-diphenyl-1-picrylhydrazyl hydrate assay}

One millilitre $(1 \mathrm{~mL})$ of $0.3 \mathrm{mM} \mathrm{2,2-}$ diphenyl-1-picrylhydrazyl hydrate DPPH in methanol was added to $1 \mathrm{~mL}$ of different concentrations $(10,5,2.5,1.25,0.625$, $0.3125 \mathrm{mg} / \mathrm{mL}$ ) of extracts and ascorbic acid standard. The reaction mixture was mixed and incubated in the dark for 30 minutes after which the absorbance was read at $517 \mathrm{~nm}$ against a DPPH control containing only $1 \mathrm{~mL}$ methanol in place of the extract. The radical scavenging ability was determined using the stable radical DPPH $(2,2-$ diphenyl-1-picrylhydrazyl hydrate) as described by Brand-Williams. ${ }^{9}$

The percentage of inhibition was calculated as follows

$$
\mathrm{I} \%=\left[\left(\mathrm{A}_{\text {blank }}-\mathrm{A}_{\text {sample }}\right) / \mathrm{A}_{\text {blank }}\right] \times 100
$$

where $A_{\text {blank }}$ is the absorbance of the control and $\mathrm{A}_{\text {sample }}$ is the absorbance of extracts and standard

\section{Nitric oxide scavenging activity}

The reaction mixture contained $0.1 \mathrm{~mL}$ of different concentrations $(10,5,2.5,1.25$ and $0.625 \mathrm{mg} / \mathrm{mL}$ ) of extracts and $0.9 \mathrm{~mL}$ of sodium nitroprusside $(2.5 \mathrm{mM})$ in phosphate buffer saline. It was incubated under illumination for 150 minutes. After incubation, $0.5 \mathrm{~mL}$ of $1 \%$ sulphanilamide in $5 \%$ phosphoric acid was added and incubated in the dark for 10 minutes, followed by addition of $0.5 \mathrm{~mL} \quad 0.1 \%$ NED (N-1napthylethylenediamine dihydrochloride). The absorbance of the chromophore formed was measured at $546 \mathrm{~nm}$. Nitric oxide radical activity of the extract was carried out according to the method of Green, ${ }^{10}$ as described by Marcocci. ${ }^{11}$ The percentage inhibition of nitric oxide radical formation was calculated as expressed above in DPPH radical scavenging assay.

\section{Hydrogen peroxide scavenging activity}

Ethanol and Methanol extracts (100 $\mu \mathrm{g} / \mathrm{mL}$ ) was dissolved in $3.4 \mathrm{~mL}$ of $0.1 \mathrm{M}$ phosphate buffer ( $\mathrm{pH}$ 7.6). It was further mixed with $0.6 \mathrm{~mL}$ of $43 \mathrm{mM}$ hydrogen peroxide solution. Absorbance value was measured at $230 \mathrm{~nm}$ of the reaction mixture after 40 minutes. BHT $(100 \mu \mathrm{g} / \mathrm{mL})$ was used as standard antioxidant. The percentage of scavenged hydrogen peroxide of was calculated using the following equation:

$$
\mathrm{I} \%=\left[\left(\mathrm{A}_{\text {blank }}-\mathrm{A}_{\text {sample }}\right) / \mathrm{A}_{\text {blank }} \times 100\right]
$$

where $A_{\text {blank }}$ is the absorbance of the control and $\mathrm{A}_{\text {sample }}$ is the absorbance of extracts and standard.

\section{Evaluation of lipid peroxidation}

Lipid peroxidation was determined by addition of $0.5 \mathrm{~mL}$ of extracts, $0.5 \mathrm{~mL}$ of phosphate buffer $(0.1 \mathrm{M}, \mathrm{pH} 8.0)$ and 0.5 $\mathrm{mL}$ of $24 \%$ TCA. The reaction mixture was
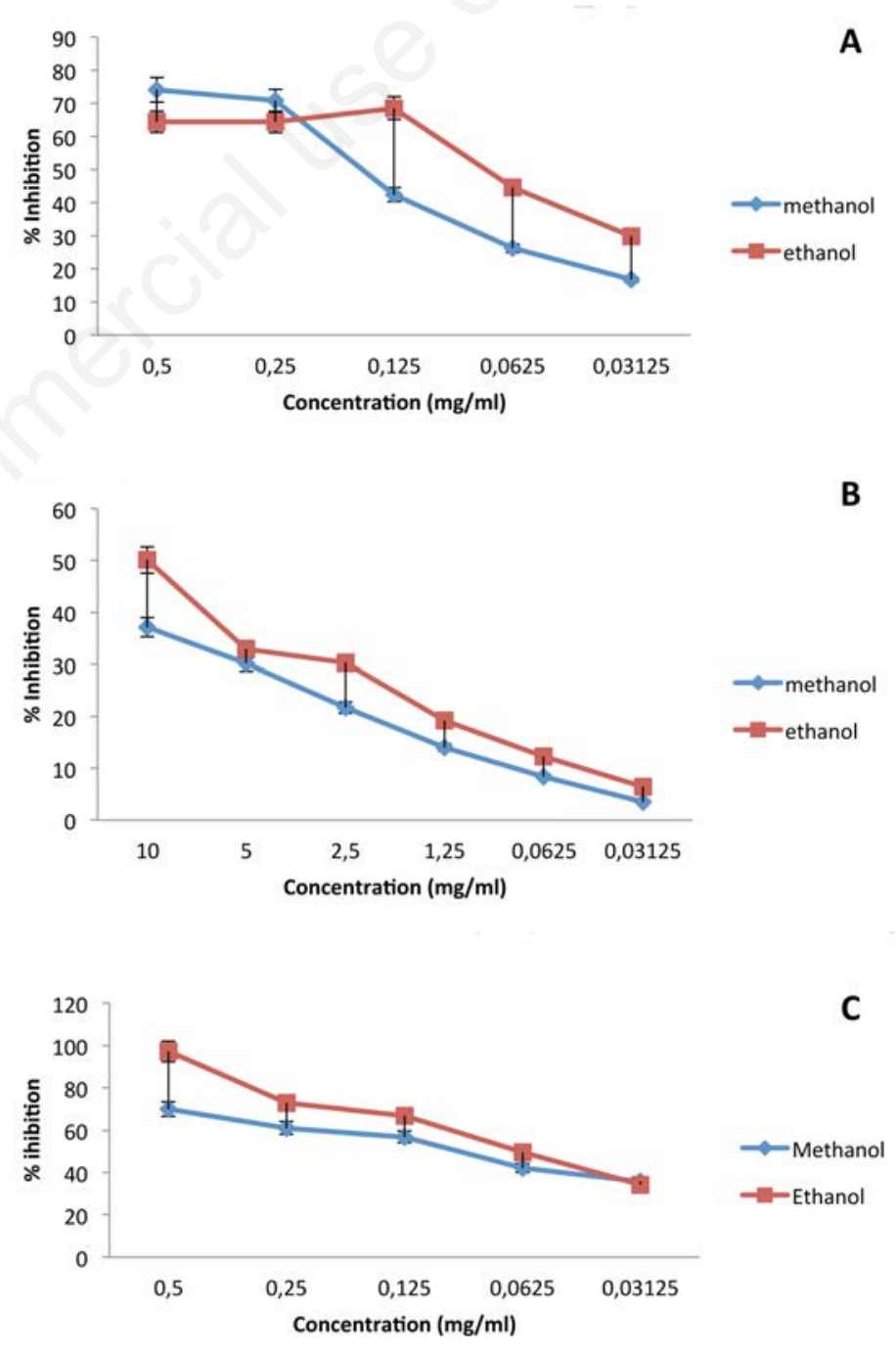

Figure 1. Scavenging activities of finger millet A) DPPH B) nitric oxide C) $\mathrm{H}_{2} \mathrm{O}_{2}$. 
incubated at room temperature for $10 \mathrm{~min}$ utes, followed by centrifugation at 2000 rpm for 20 minutes. One millilitre $(1 \mathrm{~mL})$ of supernatant was added to $0.25 \mathrm{~mL}$ of $0.33 \%$ TBA in $20 \%$ acetic acid. The reaction mixture was boiled at $95^{\circ} \mathrm{C}$ for 1 hour. The pink colour product was cool and absorbance was read at $532 \mathrm{~nm}$. The extracts were estimated by the thiobarbituric acid (TBA) method which measures the malondialdehyde (MDA) reactive products according to the method of Ohkawa ${ }^{12}$ (Extinction coefficient of MDA, $\left.\varepsilon 532=1.53 \times 105 \mathrm{~m}^{-1} \mathrm{~cm}^{-1}\right)$.

\section{Results and Discussion}

\section{Antioxidant potential of finger millet}

Phenolics acids are identified in the whole grain of finger millet. These are compound containing of phenolics ring and an organic carboxylic which help to unwaved and decolourize unpaired electrons, conferring an antioxidant property to phenolics ring. ${ }^{13,14}$ Whereas, total flavonoids are recognized with ability to donate electrons and stop chain reactions. ${ }^{15}$ Whole grain finger millet contained 14.65-38.19 mg Que/g sample of flavoniods, 36.46-67.10 mg $\mathrm{GAE} / \mathrm{g}$ sample of total phenolics with 17.61-35.89 mg AAE/g sample of total antioxidant capacity (Table 1).

Ethanolic solvent extracted $61 \%$ of flavonoids, $45 \%$ of total phenolics and $51 \%$ of total antioxidant capacity more than methanol extract (Table 1). Thus, ethanol is more efficient in extraction of antioxidant components of finger millet than methanol. The amount of total phenolics and flavonoids present revealed the concealed medicinal importance of consuming whole grain finger millet than other cereals. It was reported that buckwheat (Fagopyrum tartaricum Gaertn.) contained 8.76-16.43 mg GAE/g dry weight sample equivalent. Nevertheless, Guo et al. (2011) claimed that buckwheat contained higher total phenolics than fruits (cranberry and appple), vegetable and other cereals (wheat, oat, rice and corn). ${ }^{16}$ Whereas, total phenolics in ethanol extract of whole grain finger millet was $76 \%$ higher than phenolics in buckwheat. Total phenolics in whole grain rice ranged 0.23-3.87 mg GAE/g, maize 0.15-
$3.67 \mathrm{mg} \mathrm{GAE} / \mathrm{g}$, wheat $0.21-5.95 \mathrm{mg}$ GAE/g, oat $0.28-3.30 \mathrm{mg}$ GAE/g, barley 0.38-4.08 mg GAE/g. ${ }^{17-19}$ These obviously showed that total phenolics in whole grain finger millet was not to be compare with the common whole grains cereals crops largely consume daily by people. Whereas, awareness on the cultivation of finger millet in the globe is very low and also, it was noted the consumption of finger millet were majorly associated with an indigent people.

\section{Free radical scavenging activities of finger millet}

The ethanol extract scavenged free radicals than methanol except for DPPH at 5 $\mathrm{mg} / \mathrm{mL}$ which showed higher significance difference than that of ethanol extract. Ethanol extract of finger millet scavenged $\mathrm{NO}, \mathrm{H}_{2} \mathrm{O}_{2}$ and DPPH free radicals above $50 \%$ (Figure 1). Interestingly, percentage inhibition of hydrogen peroxide ranges from $34.28-97.15 \%$ depending on the concentration used. Whereas, DPPH and NO free radicals ranges from $29.79-68.58 \%$ and 6.44-50.09\%. Ethanol extract of whole grain finger millet was good and effective scavengers of hydrogen peroxide, nitric oxide and hydrogen atom donated from DPPH stable radical that can be produce in plant and animal under oxidation stress (Figure 1).
This could be associated to high amount of total phenolic present in the plant which generally function as a stabilizer of free radicals in body of organisms. Also, the percentages of inhibition of free radicals increase with an increase in concentration. Recently, $\mathrm{H}_{2} \mathrm{O}_{2}$ has also been shown to act as a key regulator in a broad range of physiological processes such as senescence, ${ }^{20}$ photorespiration and photosynthesis, ${ }^{21}$ stomatal movement, ${ }^{22}$ cell cycle, ${ }^{23}$ and growth and development. ${ }^{24}$ To some extent, excess $\mathrm{H}_{2} \mathrm{O}_{2}$ accumulation can lead to oxidative stress in plants, which then triggers cell death. Excess concentrations of ROS results in oxidative damage to or the apoptotic death of cells, Development of an antioxidant defence system in plants protects them against oxidative stress damage. In variably, finger millet could stand as resistant against any abiotic stress that could lead to production of hydrogen peroxide and nitric oxide. Similarly, Hydrogen peroxide $\left(\mathrm{H}_{2} \mathrm{O}_{2}\right)$ plays a major role in animal as well.

\section{Activities of whole grain finger mil- let on lipid peroxidation}

Production of high levels of free radicals or reactive oxygen species (ROS) as result of autoxidation or photo-oxidation can inflict direct damage to lipids. This

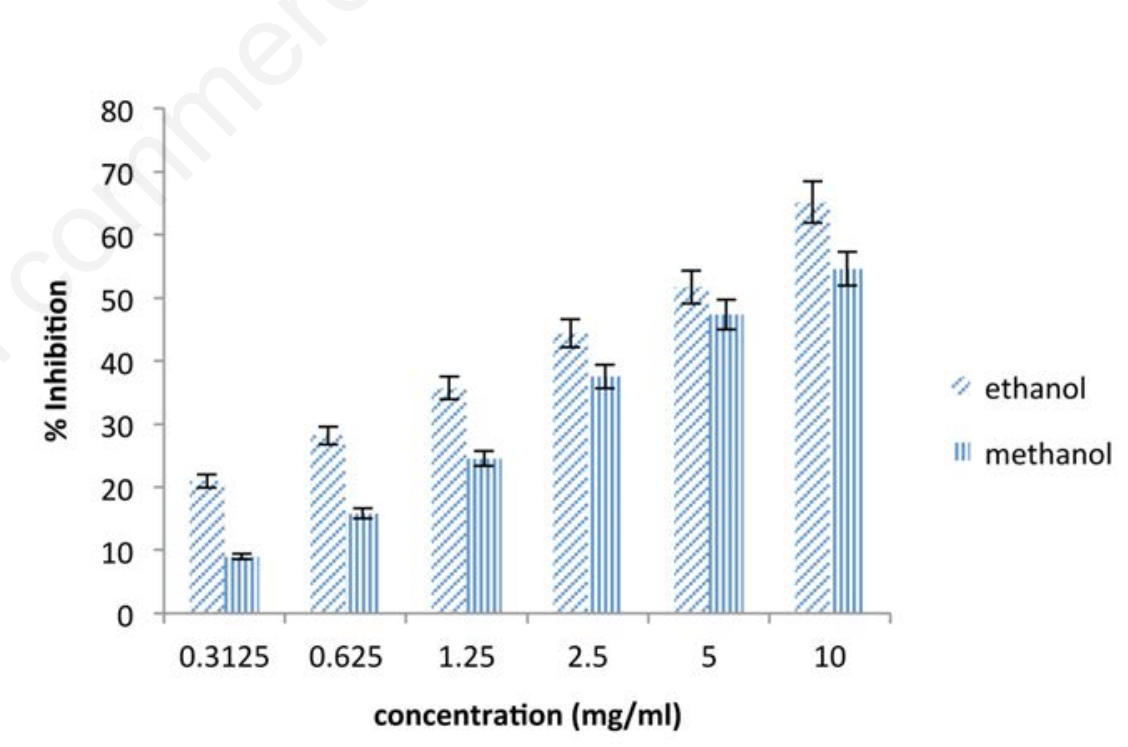

Figure 2. Inhibitory percentage of whole grain finger millet on lipid peroxidation.

Table 1. Antioxidant Activities of whole grain Finger millet.

\begin{tabular}{lccc} 
Extracts & Total flavonoids, $\mathrm{mg}$ QUE/g sample & Total phenol, $\mathrm{mg}$ GAE/g sample & Total antioxidant capacity, mg AAE/g sample \\
Methanol & $14.65 \pm 0.41$ & $36.46 \pm 1.09$ & $17.61 \pm 0.70$ \\
Ethanol & $38.19 \pm 0.60$ & $67.10 \pm 1.17$ & $35.90 \pm 1.319$ \\
\hline
\end{tabular}

Average means \pm standard error. 
involves the oxidative degradation of lipid in both plant and animal with the production and propagation of lipids radicals from polyunsaturated fatty acids. ${ }^{25,26}$ Whole grain finger millet has shown a significant termination of the lipid radical chain with an average percentage inhibition that ranged from $8.97-65.16 \%$ (Figure 2). The effectiveness of the antioxidant capacity of the whole grain finger reduced the oxidation damage of lipid to a minimum level. Concentration of the extract showed a direct significant on the percentage of inhibition. Also, ethanol extract inhibit $80 \%$ than methanol extract.

\section{Conclusions}

The study revealed that whole grain finger millet contained 14.65-38.19 mg Que/g sample of flavoniods, 36.46-67.10 mg GAE/g sample of total phenolics and 17.61$35.89 \mathrm{mg}$ AAE/g sample of total antioxidant capacity with $34.28-97.15 \%, 29.79-68.58 \%$ and $6.44-50.09 \%$ percentage inhibition of $\mathrm{H}_{2} \mathrm{O}_{2}, \mathrm{DPPH}$ and NO respectively. Whole finger millet further showed termination of formation and propagation of lipid peroxidation resulted from oxidative stress of plant and animal tissues. In addition, scavenging and inhibition activities of whole grain millet were concentration dependent.

\section{References}

1. FAOSTAT. Food and Agriculture data. 2010. Available from: http://www.fao.org/faostat/en/\#home

2. Antony U, Sripriya G, Chandra TS. Effect of fermentation on the primary nutrients in finger millet (Eleusine coracana). J Agric Food Chem 1996;44: 2616-18.

3. Chethan S, Malleshi NG. Finger millet polyphenols: optimization of extraction and the effect of $\mathrm{pH}$ on their stability. Food Chem 2007;105:862-70

4. Percival M. Antioxidants. Clinical
Nutrition Insights. NUT031 1/96 Rev. 10/98 1996. Available from: https://acudoc.com/Antioxidants.PDF

5. Halliwell B. Free radicals, antioxidants, and human disease: curiosity, cause, or consequence? Lancet 1994;344:721-4.

6. Sies H. Oxidative stress: oxidants and antioxidants. Exp Physiol 1997;82:2915.

7. Fang Z, Zhang Y, Lu Y, et al. Phenolic compounds and antioxidant capacities of bayberry juices. Food Chem 2009;113:884-8.

8. Prieto P, Pineda M, Aguilar M. Spectrophotometric quantitation of antioxidant capacity through the formation of a Phosphomolybdenum complex: specific application to the determination of vitamin E. Anal Biochem 1999;269:337-41.

9. Brand-Williams W, Cuvelier ME, Beset C. Use of free radical method to evaluate antioxidant activity. LWT Food Sci Technol 1995;28:25-30.

10. Green LC, Wagner DA, Glogowski J, et al. Analysis of nitrate, nitrite and $15 \mathrm{~N}$ in biological fluids. Anal Biochem 1982;126:131-6.

11. Marcocci L, Packer L, Droy-Lefai MT, et al. Antioxidant action of Ginkgo biloba extracts EGb 761. Methods Enzymol 1994;234:462-75.

12. Ohkawa H, Onishi V, Yagi K. Assay for lipid peroxidation in animal tissue by thiobarbituric acid reaction Anal Biochem 1979; 95;351-8.

13. Goufo P, Pereira J, Moutinho-Pereira J, et al. Rice (Oryza sativa L.) phenolic compounds under elevated carbon dioxide (CO2) concentration. Environ Exp Bot 2014;99:28-37.

14. Goffman FD, Bergman CJ. Rice kernel phenolic content and its relationship with antiradical efficiency. J Sci Food Agric 2004;84:1235-40.

15. Cho JG, Song NY, Nam TG, et al. Flavonoids from the grains of $\mathrm{C} 1 / \mathrm{R}-\mathrm{S}$ transgenic rice, the transgenic Oryza sativa spp. japonica, and their radical scavenging activities. J Agric Food Chem 2013;61:10354-9.
16. Guo X, Ma Y, Parry J, et al. Phenolics content and antioxidant activity of tartary buckwheat from different locations. Molecules 2011;16: 9850-67.

17. Goufo P, Trindade H. Rice antioxidants: phenolic acids, flavonoids, anthocyanins, proanthocyanidins, tocopherols, tocotrienols, $\gamma$-oryzanol, and phytic acid. Food Sci Nutr 2014;2:75104.

18. Abdel-Aal EM, Young JC, Rabalski I. Anthocyanin composition in black, blue pink, purple and red cereal grains. J Agric Food Chem 2006;54:4696-704.

19. Adebiyi AP, Adebiyi AO, Yamashita J, et al. Purification and characterization of antioxidant peptides derived from rice bran protein hydrolysates. Eur Food Res Technol 2009;228:553-63.

20. Peng LT, Jiang YM, Yang SZ, Pan SY. Accelerated senescence of fresh-cut Chinese water chestnut tissues in relation to hydrogen peroxide accumulation. Plant Physlmolbi 2005;31:527-32.

21. Noctor G, Foyer CH. Ascorbate and glutathione: keeping active oxygen under control. Ann Rev Plant Physiol Plant Mol Biol 1998;49:249-79.

22. Bright J, Desikan R, Hancock JT, et al. ABA-induced NO generation and stomatal closure in Arabidopsis are dependent on $\mathrm{H} 2 \mathrm{O} 2$ synthesis. Plant J 2006;45:13-122.

23. Mittler R, Vanderauwera S, Gollery M, Van Breusegem F. Reactive oxygen gene network of plant. Trends Plant Sci 2004;9:490-8.

24. Foreman J, Bothwell JH, Demidchik V, et al. Reactive oxygen species produced by NADPH oxidase regulate plant cell growth. Nature 2003;422:442-6.

25. Repetto M, Semprine J, Boveris A. Lipid peroxidation: chemical mechanism, biological implications and analytical determination. INTECH, 2012.

26. Dianzani M, Barrera G. Pathology and physiology of lipid peroxidation and its carbonyl products. In: Álvarez S, Evelson P, eds. free radical pathophysiology. Kerala: Transworld Research Network; 2008. pp 19-38. 